\title{
Diagnosis of Frontal Instabilities over the Southern Ocean
}

\author{
Jérôme Patoux, Gregory J. Hakim, And Robert A. Brown \\ Department of Atmospheric Sciences, University of Washington, Seattle, Washington
}

(Manuscript received 19 March 2004, in final form 11 August 2004)

\begin{abstract}
The development of three fronts over the Southern Ocean is described using SeaWinds-on-QuikSCAT scatterometer surface winds and an attribution technique to partition the wind field in three components: nondivergent and irrotational components at the scale of the front, and the remaining harmonic component (or environmental flow) induced by the synoptic-scale flow. The front and the environment in which the front is embedded are analyzed separately.

A frontal wave is shown to develop out of the first front when the large-scale alongfront stretching decreases, the environmental flow becomes frontolytic, and a connection with the upper levels is established. In the second case, the stretching remains relatively strong and no frontal wave develops. The third front exhibits a developing wave but is not in a favorable configuration with the upper levels; the frontal wave does not deepen significantly.
\end{abstract}

\section{Introduction}

Atmospheric fronts are subject to instability. They are characterized by strong wind shear and a maximum in vorticity (i.e., an inflection point, in the sense of the Rayleigh criterion for instability). Given appropriate environmental conditions, perturbations on fronts can grow and extract energy from the wind shear. This is predicted by theory (Charney and Stern 1962; Schär and Davies 1990) and observed in satellite images (Evans et al. 1994) and numerical analyses (e.g., Joly and Thorpe 1990; Thorncroft and Hoskins 1990).

Midlatitude cold fronts often survive their parent cyclone for several days (e.g., Patoux 2003). Some fronts eventually decay, but others spawn frontal waves on the order of $1000 \mathrm{~km}$ that can rapidly develop (in 1 or 2 days) and can be relatively difficult to forecast. Recently, there has been a renewed interest in frontal wave development (Parker 1998), especially west of the British Isles and western Europe (Rivals et al. 1998; Joly et al. 1997). Little has been written about other regions of the world, such as the Southern Hemisphere, which is the topic of this paper.

Several studies have emphasized the role of warm bands and latent heat release in creating low-level bands of potential vorticity (PV) subject to instabilities (Schär and Davies 1990; Joly and Thorpe 1990, 1991).

Corresponding author address: Jérôme Patoux, Department of Atmospheric Sciences, University of Washington, 408 ATG Building, Box 351640, Seattle, WA 98195-1640.

E-mail: jerome@atmos.washington.edu
However, it has also been shown that although barotropic frontal perturbations can grow and distort the frontal structure, they typically saturate within 2 days at amplitudes weaker than the parent cyclone (Malardel et al. 1993; Joly 1995). In contrast, frontal waves that continue to develop beyond the initial barotropicbaroclinic growth phase appear to couple with an upper-level disturbance, producing a second baroclinic deepening phase (Thorncroft and Hoskins 1990; Bouniol et al. 1999, 2002; Mallet et al. 1999).

The advent of satellite scatterometers has enriched our view of the atmosphere over the oceans (Liu 2002). There is now ample evidence that scatterometer winds contain more information than is available from model analyses that do not assimilate these winds (Atlas et al. 1999). In July 1999 the SeaWinds-on-QuikSCAT (QS) scatterometer was launched and has been providing an almost continuous set of surface wind measurements over most of the World Ocean to this day. On the larger scale, the recurrent period of the QS measurements provides a quasi-synoptic look at the world marine surface wind field. On the smaller scale, the $25-\mathrm{km}$ grid spacing provides an opportunity to study mesoscale features embedded in fronts. Only when decreasing the resolution of the Goddard Earth Observing System general circulation model $(\mathrm{GCM})$ to $0.5^{\circ} \times 0.5^{\circ}$ do Conaty et al. (2001, p.1854) produce frontal features that are "reminiscent of those seen in high-resolution scatterometer wind data." Scatterometer data have been used to study the development of storms in the Southern Hemisphere (Levy and Brown 1991; Levy 1989, 1994; McMurdie and Katsaros 1991; Yuan et al. 
1999; Milliff et al. 1999; Hilburn et al. 2003) and fronts or frontogenesis (Zierden et al. 2000; Yeh et al. 2002) but not to study frontal instabilities. The goal of this study is to apply an attribution technique to scatterometer data to analyze the development of three fronts over the Southern Ocean. The technique is used to reconstruct the environmental flow in which the fronts are embedded and analyze the impact of this flow on the development of the fronts.

The attribution technique was developed by Bishop (1996a) to assess the impact of stretching deformation on the development of frontal waves. Bishop and Thorpe's (1994) study of an idealized frontal wave model suggested that in the early stages of frontal evolution deformation acts to intensify the PV extremum while at the same time suppressing wave growth. If the alongfront stretching due to the basic-state deformation field decreases under a certain threshold at a later stage, wave(s) can transition from a linear to a nonlinear mode and grow out of the unstable structure. Their idealized model gave a strain rate of $0.6 \times 10^{-5} \mathrm{~s}^{-1}$ as the threshold over which frontal waves cannot make that transition and therefore cannot grow significantly. Their analytical model assumed free-slip boundary condition, zero viscosity, semigeostrophy, zero moist potential vorticity, $100 \%$ humidity, and uniform strain. Given the idealized nature of Bishop and Thorpe's model, its quantitative predictions should be viewed with more caution than its qualitative ones. Nevertheless, the prediction of a critical strain rate for frontal wave development motivated the attribution technique of Bishop (1996a) to estimate the environmental strain rate from observations. Renfrew et al. (1997) and Rivals et al. (1998) applied this technique to observational studies of frontal wave development over the North Atlantic Ocean.

Renfrew et al. (1997) analyzed 20 samples drawn from 4 distinct cases of frontal waves and found 16 that were consistent with Bishop and Thorpe's threshold, including 5 cases of decaying cyclones in strong strain environments and 11 cases of growing frontal waves in weak strain environments. Rivals et al. (1998) analyzed a frontal wave in its initiation phase and found it growing in a part of the front where the environmental strain had decreased below $0.6 \times 10^{-5} \mathrm{~s}^{-1}$. Although the two observational studies are broadly consistent with Bishop and Thorpe's theoretical results, the analyzed cases remain limited in number and confined to a specific geographic area. To test if the theory is universally applicable, additional case studies in new regions are needed. One of the goals of this study is to analyze three new cases of frontal development, and to do so over the Southern Ocean using scatterometer wind measurements.

Section 2 describes the datasets and the methodology used to study the development of the marine surface fronts. In section 3 three fronts are described and the results are discussed. A concluding discussion is provided in section 4

\section{Methodology}

\section{a. Data}

The SeaWinds-on-QuikSCAT Jet Propulsion Laboratory $\mathrm{L} 2 \mathrm{~B}$ surface wind vectors are interpolated onto a $50-\mathrm{km}$ grid after discarding the vectors flagged for rain contamination (Wentz and Smith 1998). The choice of $50 \mathrm{~km}$ is a compromise between resolution and computation time. Global operational surface temperatures at synoptic times obtained from the European Centre for Medium-Range Weather Forecasts (ECMWF) are interpolated from a $1.25^{\circ} \times 1.12^{\circ}$ grid to the $50-\mathrm{km}$ grid used to partition the wind. Note that the three cases investigated in this study took place before ECMWF assimilation of QS measurements. Composite satellite images were obtained from the Global Hydrology Resource Center (http://ghrc.msfc.nasa.gov). They construct hourly images covering most of the planet from measurements by the four geostationary satellites, Geostationary Operational Environmental Satellite-8 (GOES-8) and -10 (GOES-10), Geostationary Meteorological Satellite-5 (GMS-5), and Meteosat-7 (Kidder and Vonder Haar 1995).

A planetary boundary layer model is used to estimate the surface pressure field from the QS surface wind measurements. The model assumes gradient wind balance at each point of the swath and calculates the corresponding pressure gradient. A pressure field is fit to the swath of pressure gradients by least squares optimization. The model and technique are described and evaluated in Brown and Levy (1986) and Patoux et al. (2003). The model has been applied in Patoux and Brown (2002) and Brown and Zeng (1994). Hereafter, the resulting surface pressure fields will be referred to as QS-derived pressure fields.

\section{b. Partitioning of the wind}

Underlying the different models of frontogenesis is the assumption that there exists some interaction between the front - a mesoscale feature characterized by strong turning of the wind and consequently strong wind shear and vorticity-and the synoptic-scale flow. In theoretical studies, this large-scale flow is often represented by a pure deformation field, whereas the embedded front is typically modeled as a shear or vorticity line (Keyser and Pecnick 1985). To compare observations with theory and idealized modeling studies, the flow near a front also needs to be partitioned into contributions from the front and from the larger scales. One approach involves a Helmholtz decomposition into rotational and divergent flow components with piecewise attribution to flow elements associated with the front and the environment. Although this is 
straightforward on the sphere, results for a limited-area domain, such as those we consider here, can be sensitive to boundary conditions (Lynch 1989). This issue motivated Bishop (1996a,b) to develop an attribution technique using free-space (boundary free) Green's functions to extract the front from its environment and to study the influence of the environmental flow on the development of the front. Since the approach used by Bishop (1996a) has been adopted and described several times in the recent literature (Renfrew et al. 1997; Rivals et al. 1998), we will only briefly summarize it here. The method consists of identifying the front with a strip of vorticity and convergence and reconstructing the corresponding nondivergent $\left(u_{\psi}\right)$ and irrotational $\left(u_{\chi}\right)$ wind components. By subtraction from the total wind, the environmental flow can be calculated.

We index a grid by $1<k<M-1$ along the $x$ coordinate and $1<l<N-1$ along the $y$ coordinate. A vorticity element, $C_{k l}$, centered at $\left(x_{k l}^{\prime}, y_{k l}^{\prime}\right)$ contributes to the wind at any point $(x, y)$. By adding all the contributions from vorticity elements throughout the grid, one reconstructs the total nondivergent wind field induced at $(x, y)$ :

$$
\begin{gathered}
u_{\psi}(x, y)=\frac{1}{2 \pi} \sum_{k=1}^{M-1} \sum_{l=1}^{N-1} C_{k l} \frac{-\left(y-y_{k l}^{\prime}\right)}{r_{k l}^{2}}, \\
v_{\psi}(x, y)=\frac{1}{2 \pi} \sum_{k=1}^{M-1} \sum_{l=1}^{N-1} C_{k l} \frac{\left(x-x_{k l}^{\prime}\right)}{r_{k l}^{2}}
\end{gathered}
$$

where $r_{k l}$ is the distance between $(x, y)$ and each vorticity element $C_{k l}$. Similarly the sum of the contributions from discrete divergence element $F_{k l}$ represents the irrotational wind component induced at point $(x, y)$ :

$$
\begin{aligned}
& u_{\chi}(x, y)=\frac{1}{2 \pi} \sum_{k=1}^{M-1} \sum_{l=1}^{N-1} F_{k l} \frac{\left(x-x_{k l}^{\prime}\right)}{r_{k l}^{2}}, \\
& v_{\chi}(x, y)=\frac{1}{2 \pi} \sum_{k=1}^{M-1} \sum_{l=1}^{N-1} F_{k l} \frac{\left(y-y_{k l}^{\prime}\right)}{r_{k l}^{2}} .
\end{aligned}
$$

These two wind fields [Eqs. (1) and (2)] are the nondivergent and the irrotational components of the total wind field induced by vorticity and divergence elements attributed to the front for suitably chosen $C_{k l}$ and $F_{k l}$. Thus $\boldsymbol{u}_{\psi}$ (bold indicates a vector) contains the geostrophic and the nondivergent ageostrophic components of the wind, whereas $\boldsymbol{u}_{\chi}$ contains the divergent ageostrophic component. By subtraction, the remaining component $\boldsymbol{u}_{\theta}=\boldsymbol{u}-\boldsymbol{u}_{\psi}-\boldsymbol{u}_{\chi}$ is irrotational and nondivergent, and is induced by vorticity and divergence elements outside the frontal region (i.e., surrounding synoptic-scale features). It thus represents the "background" wind, or "environmental" wind, which is typically modeled as a pure deformation wind field. Bishop's attribution technique provides a convenient way of estimating $\boldsymbol{u}_{\theta}$ from wind analyses. It is adapted here to estimate $\boldsymbol{u}_{\theta}$ from QS wind measurements. The reader is referred to Bishop (1996a) and Patoux (2003) for further details and discussion about the technique.

\section{c. Example}

The attribution technique is illustrated with an example over the Southern Ocean, west of Chile, on 25 July 1999 at 1300 UTC. The figure has been rotated so that the front is aligned with the vertical axis of the page. These rotated coordinates define the $x$ axis (across the front, pointing toward the warm air) and the $y$ axis of the frontal box. Figure 1a shows a QS swath in which the pressure field is indicated with 4-hPa thick contours and the divergence field with colors and thin contours. A trailing cold front is visible around $34^{\circ} \mathrm{S}$ with the corresponding mature system located south of the Drake Passage. The front is located between two anticyclones $\left[\left(95^{\circ} \mathrm{W}, 30^{\circ} \mathrm{S}\right)\right.$ and $\left.\left(110^{\circ} \mathrm{W}, 37^{\circ} \mathrm{S}\right)\right]$ such that there exists a saddle point (or "col") at $\left(100^{\circ} \mathrm{W}\right.$, $35^{\circ} \mathrm{S}$ ). The signature of the front is clearly visible in the divergence field. A box is drawn around the front, as indicated in the figure by a thick black rectangle. Figure $1 \mathrm{~b}$ is an enlargement of the frontal box showing both the line of convergence (background yellow and orange colors) and the QS winds. The box is $1000 \mathrm{~km}$ wide and $2000 \mathrm{~km}$ long with 50-km resolution.

The wind partitioning using the attribution technique described above is shown in Fig. 2, which shows $\boldsymbol{u}_{\psi}, \boldsymbol{u}_{\chi}$, and $\boldsymbol{u}_{\theta}$, respectively. One can clearly appreciate how $\boldsymbol{u}_{\psi}$ describes the "vortical" part of the flow and $\boldsymbol{u}_{\chi}$ describes the convergent part of the flow. One also notes that the remaining environmental flow $\boldsymbol{u}_{\theta}$ shares some similarities with a pure deformation flow. One of our goals is to determine how $\partial v_{\theta} / \partial y$, the stretching in the alongfront direction associated with this deformation, affects the development of the fronts. In the rest of this study, $\partial v_{\theta} / \partial y$ will be averaged along the front and will be referred to as the average alongfront stretching by the environmental flow or, because the environmental flow is divergence free, simply the strain rate.

\section{d. Sensitivity analysis}

Errors in the strain rate estimates have two origins: 1) errors in the QS wind estimates inherent to the measuring device and to the model function used to retrieve wind speed and wind direction from the measurements and 2) errors in the positioning of the frontal box along the front. The total error was evaluated in the 25 July 1200 UTC case by adding Gaussian noise to the speed (direction) of the QS winds with a $1 \mathrm{~m} \mathrm{~s}^{-1}\left(15^{\circ}\right)$ standard deviation corresponding to the rms error in the QS wind speed (direction), as well as a Gaussian noise of $3^{\circ}$ standard deviation to the angle of the frontal box. This resulted in a $0.05 \times 10^{-5} \mathrm{~s}^{-1} \mathrm{rms}$ error in the alongfront strain rates, which we assume is characteristic of the uncertainty for the cases shown here. 

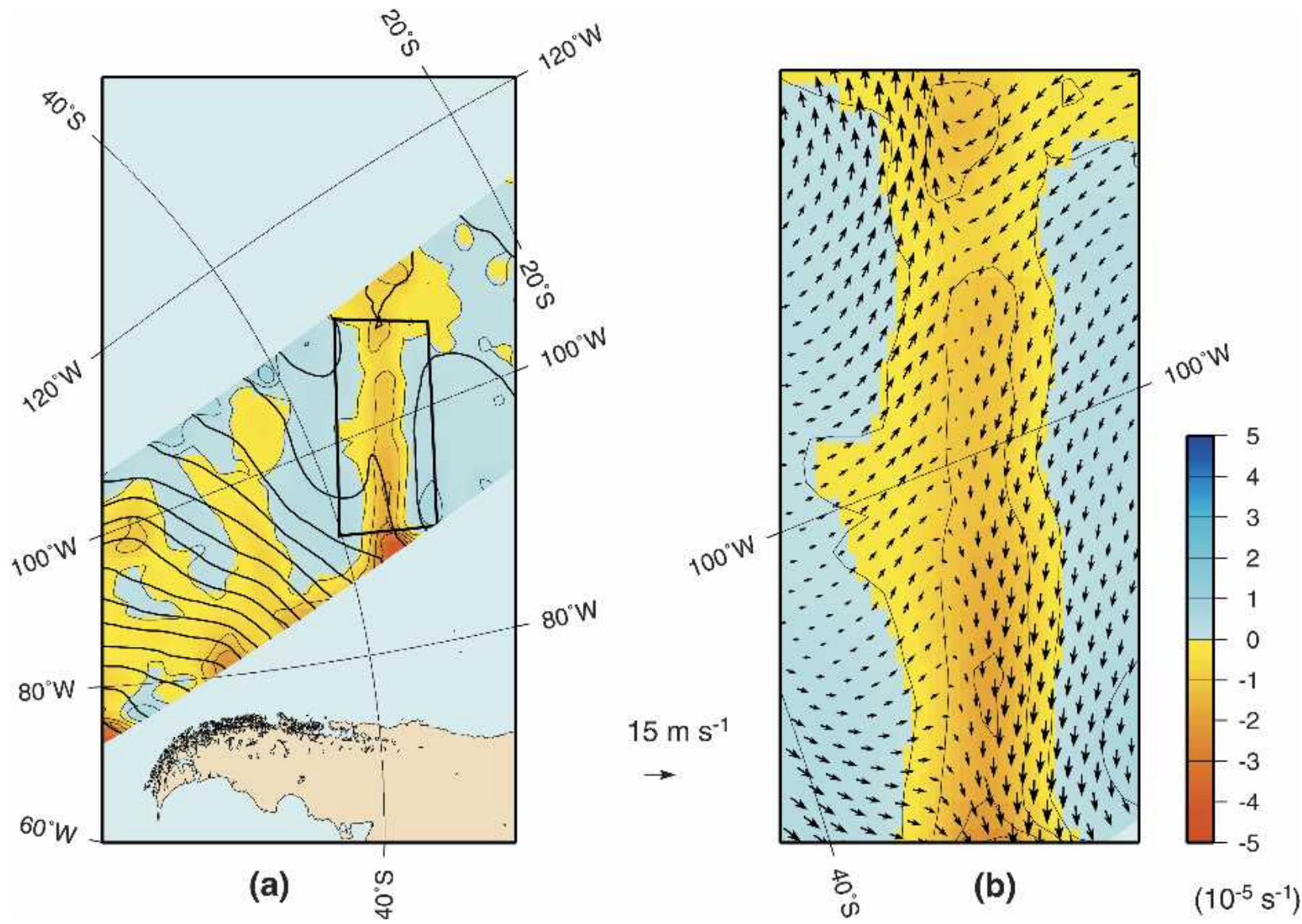

FIG. 1. Two views of a front on 25 Jul 1999 at 1300 UTC: (a) QS-derived surface pressure (4-hPa contours) and divergence with frontal box shown around the front, and (b) divergence and winds in the frontal box.

\section{e. Frontogenesis}

Following Keyser et al. (1988) and Rivals et al. (1998) we define surface frontogenesis as

$$
\begin{aligned}
& F_{x}=\frac{d}{d t}\left(\frac{\partial T}{\partial x}\right)=-\frac{\partial u}{\partial x} \frac{\partial T}{\partial x}-\frac{\partial v}{\partial x} \frac{\partial T}{\partial y}, \\
& F_{y}=\frac{d}{d t}\left(\frac{\partial T}{\partial y}\right)=-\frac{\partial u}{\partial y} \frac{\partial T}{\partial x}-\frac{\partial v}{\partial y} \frac{\partial T}{\partial y},
\end{aligned}
$$

where $d / d t$ represents a material derivative. Since Eq. (3) is linear in the wind field, $u$ and $v$ can denote any of the three components of the wind identified above, $u_{\psi}$, $u_{\chi}$, or $u_{\theta}$, so that frontogenesis can be investigated as the sum of three constituents:

$$
F_{0}=F_{\psi}+F_{\chi}+F_{\theta},
$$

namely, frontogenesis due to the nondivergent flow, frontogenesis due to the divergent ageostrophic ${ }^{1}$ cross-

\footnotetext{
${ }^{1}$ Given the small horizontal scale of frontal waves, we define the geostrophic wind with a constant local value of the Coriolis parameter; therefore the geostrophic wind is nondivergent.
}

frontal ${ }^{2}$ wind, and frontogenesis due to the environmental flow. The temperature $T$ is obtained by interpolating the closest-in-time ECMWF surface air temperatures onto the frontal grid. Because frontogenesis is of interest in the vicinity of the frontal region, the different frontogenetical components are averaged over a narrower frontal box of $300-\mathrm{km}$ width centered on the front.

Note that there is a resolution difference between the frontal grid box data $(50 \mathrm{~km})$ and ECMWF data $\left(1.25^{\circ} \times 1.12^{\circ}\right)$. The fronts are not as "sharp" in the ECMWF surface air temperature fields as suggested by the QS surface winds; higher-resolution surface temperatures over the Southern Ocean are not available for these cases.

\section{Comparison of three fronts}

The above analysis is applied to three fronts exhibiting clearly different behaviors. The three cases were

\footnotetext{
${ }^{2} \mathrm{We}$ assume that the alongfront wind is nondivergent.
} 

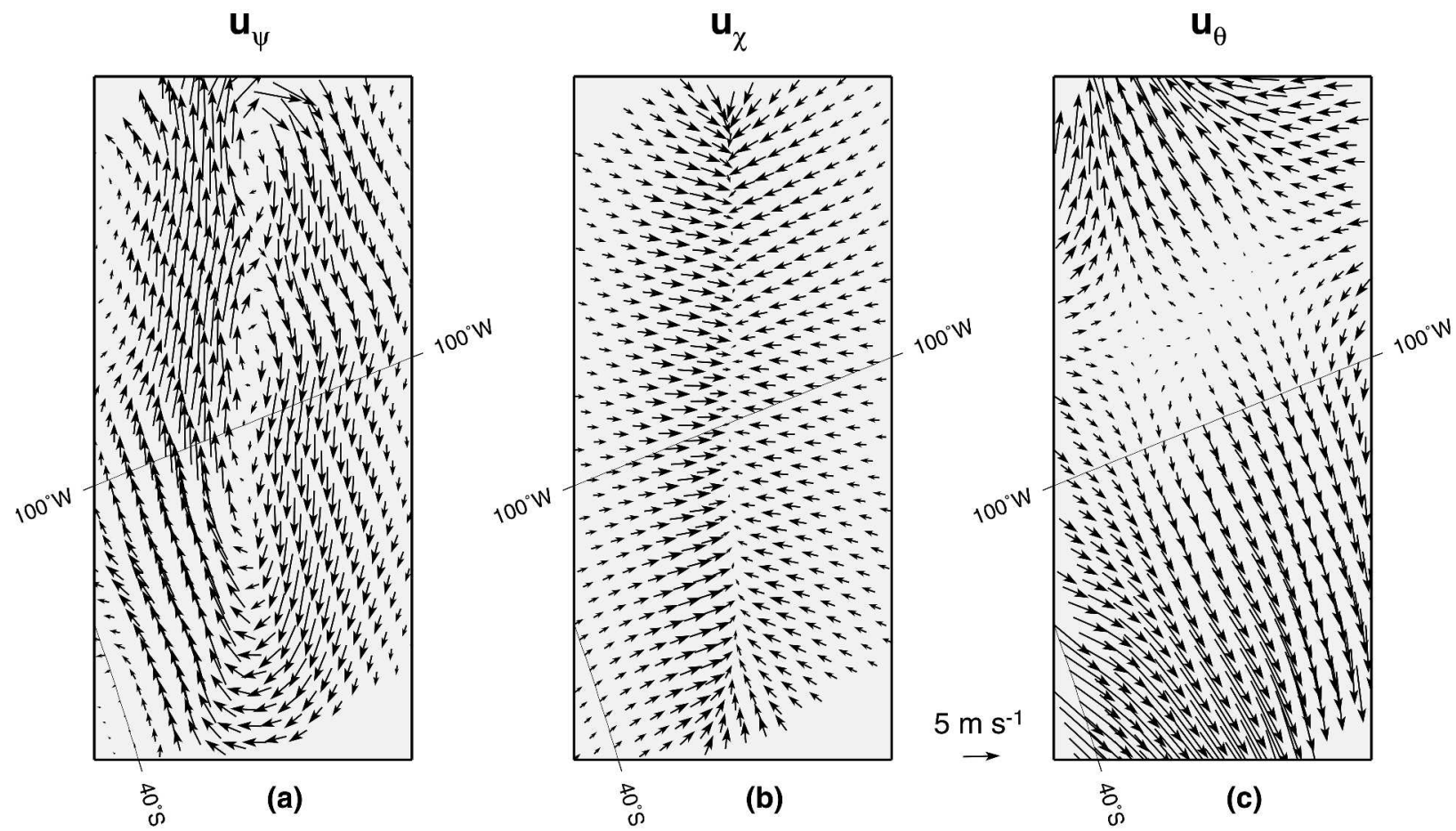

FIG. 2. Partitioning of the QS winds shown in Fig. 1b: (a) nondivergent $\boldsymbol{u}_{\psi}$, (b) irrotational $\boldsymbol{u}_{\chi}$, and (c) environmental flow $\boldsymbol{u}_{\theta}$.

chosen among a series of fronts observed during the first year of QS operation (July 1999 to June 2000). The first case was selected for its remarkably clear frontal wave signature in surface pressure, divergence, and satellite imagery. The second case was selected randomly from a large number of long-lived fronts that spawned no frontal waves. The third case was selected randomly from a limited number of fronts along which a perturbation could be observed to quickly grow and decay in $24 \mathrm{~h}$. Note that the technique is not automated and must be applied case by case. As such, establishing a climatology of fronts and frontal waves is a large task beyond the scope of this paper.

\section{a. Deepening frontal wave}

Figure 3 illustrates the development of the frontal wave used in this first analysis, off the coast of Chile. The panels are separated by roughly $12 \mathrm{~h}$, starting at 1200 UTC on 25 July 1999 in Fig. 3a to 1200 UTC on 27 July in Fig. 3e. Figure 3a also corresponds to the example shown in section $2 \mathrm{~b}$, which was described as a "col" point on a trailing cold front.

This figure shows that a frontal wave grows near the saddle point and deepens significantly $(25 \mathrm{hPa})$ in 1 day. The development first appears as a wavy pattern in the convergence line characterizing the front and as a slight depression in the surface pressure field (one closed isobar). It then grows into a tight low in the pressure field with a commalike signature in conver- gence. The infrared image also shows a comma-type cloud structure matching the convergence pattern on 27 July.

The partitioning of the wind described earlier is applied at each step of the development of the front from 24 to 28 July, and the time evolution of the alongfront stretching $\left(\partial v_{\theta} / \partial y\right)$ by the environmental flow is shown in Fig. 4. The $x$ axis is labeled in hours, starting on 24 July, at 0000 UTC. The alongfront stretching decreases over the first $60 \mathrm{~h}$ to reach its lowest value $\left(0.2 \times 10^{-5}\right.$ $\mathrm{s}^{-1}$ ) when the frontal wave starts to grow significantly (Fig. 3c). The stretching increases anew as the cold front develops, rotates and crosses over South America (not shown). The timing of the frontal wave growth with the minimum in stretching agrees with previous observational findings by Renfrew et al. (1997) and Rivals et al. (1998) that atmospheric frontal waves behave in a way that is broadly consistent with the predictions of Bishop and Thorpe's (1994) analytical model. They proposed that the strain rate should decrease below $0.6 \times 10^{-5} \mathrm{~s}^{-1}$. In the example described here, the strain rate decreases to $0.2 \times 10^{-5} \mathrm{~s}^{-1}$.

Figure 5 shows average frontogenesis due to the total wind $\left(F_{0}\right)$ and to each wind component $\left(F_{\psi}, F_{\chi}\right.$ and $\left.F_{\theta}\right)$. The general tendency of $F_{0}$ is to increase during the development of the front and reach a local maximum when the frontal wave starts to grow (at $\mathrm{t}=60 \mathrm{~h}$ ). Whereas $F_{\chi}$ and $F_{\psi}$ increase as the frontal wave develops, $F_{\theta}$ decreases to a (negative) minimum. This difference in the frontogenesis components suggests that the 

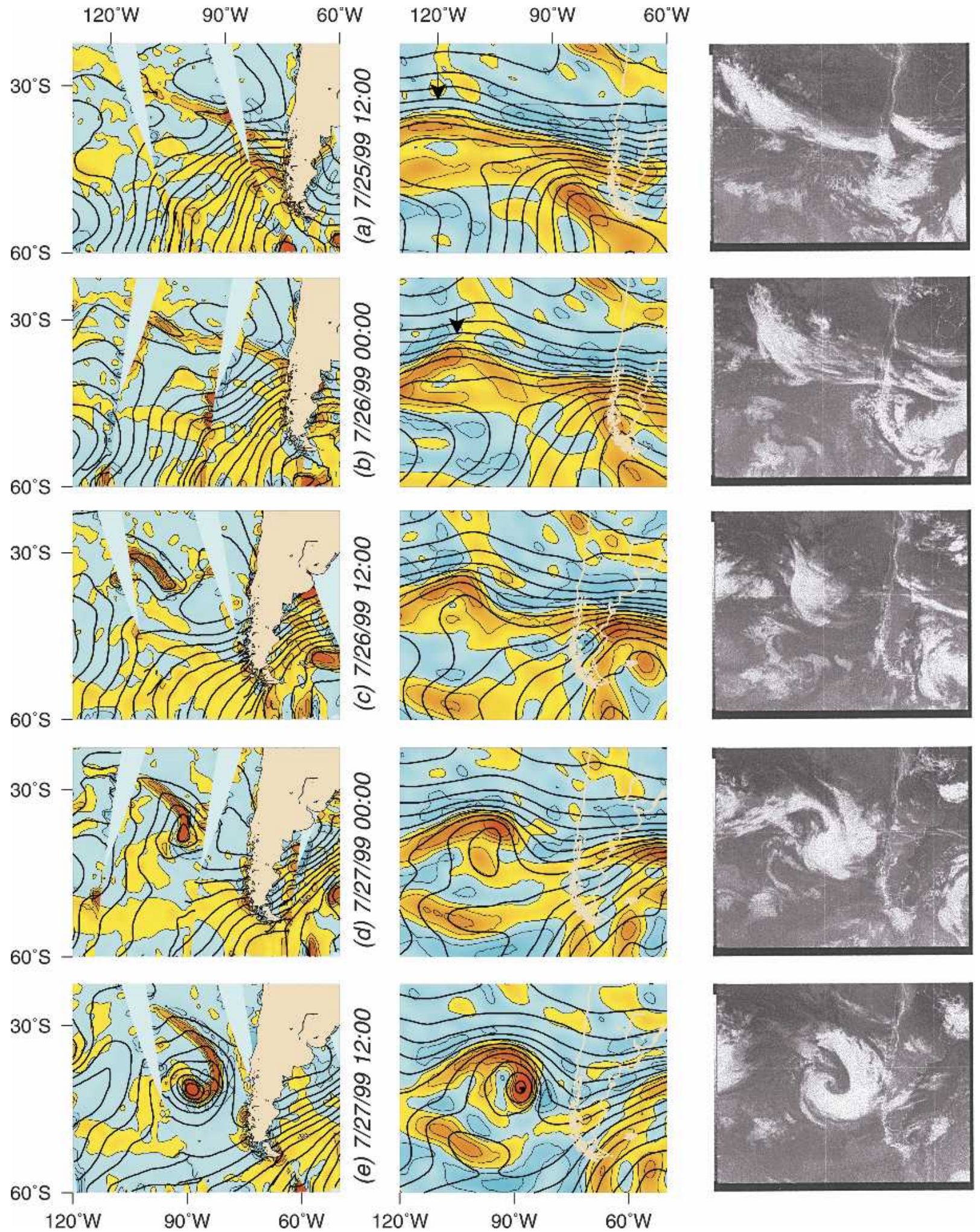

FIG. 3. Development of a frontal wave. (left) Surface divergence and pressure (4-hPa contours), (middle) 500-hPa relative vorticity and heights (60-m contours), and (right) Satellite infrared imagery. Divergence and vorticity are plotted using the same colors and scale as in Fig. 1. Panels are separated by $12 \mathrm{~h}$ from (top) 25 Jul 1999 at 1200 UTC to (bottom) 27 Jul 1999 at 1200 UTC. 


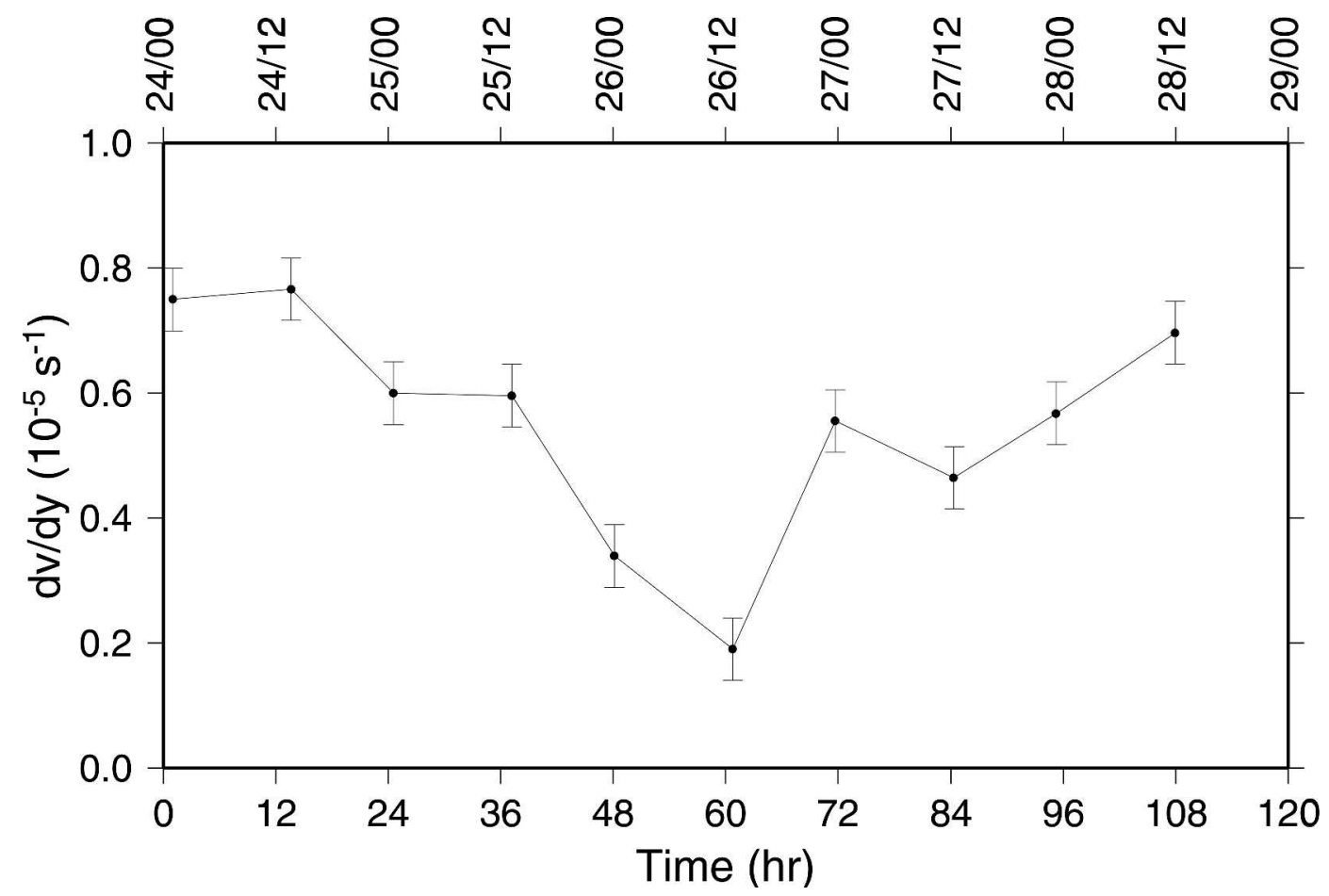

FIG. 4. Time evolution of the alongfront stretching by the environmental flow. Bottom $x$ axis indicates time from 24 Jul 1999 at 0000 UTC. Top $x$ axis indicates the date as day/time, e.g., 24/12 = 24 Jul 1999 at 1200 UTC.

cross-frontal ageostrophic circulation plays a major role in strengthening the front $\left(F_{\chi}\right)$, whereas the background deformation becomes frontolytical. Rivals et al. (1998) also find a predominant role played by the ageostrophic circulation. However, they observe that the frontal wave grows at a time when $F_{x}$ decreases. The reverse is observed in our case.

Finally we turn to the upper-level analyses shown in the middle column of Fig. 3. The main feature of interest is highlighted by arrows. As the surface front develops and strengthens, a short wave trough on the upperlevel jet approaches from the west. Its signature is weak but apparent as a wavy pattern in the 500-hPa heights and as a local maximum in vorticity. The subsequent growth of that upper-level feature is coincident with the deepening of the frontal wave beneath it, which suggests a baroclinic growing mode in the later stages.

To summarize, this first front strengthens as a result of frontogenesis due mainly to the convergent ageostrophic cross-frontal circulation. Then three processes become important: (i) The alongfront stretching associated with the environmental flow decreases with time and reaches a minimum of $0.2 \times 10^{-5} \mathrm{~s}^{-1}$. (ii) The environmental flow becomes frontolytic. (iii) An upper-level short wave approaches the surface front. A secondary cyclone develops $(25 \mathrm{hPa}$ in $24 \mathrm{~h})$, with a clear signature in both the surface and upper-level fields.

This scenario resembles typical frontal waves ob- served in the North Atlantic (e.g., Rivals et al. 1998), with the subsequent cyclone growth having a baroclinic component, as suggested by Joly (1995). However, many fronts observed with the QS data are apparently stable, long-lived, and decay without producing frontal waves (Patoux 2003). Therefore the previous analysis is now applied to a stable front and to a front in which a perturbation fails to grow.

\section{b. Stable front}

The front analyzed here is described briefly in Fig. 6. Since the front is stable and long-lived, three characteristic stages of the life cycle are presented more concisely than for the previous case (Figs. 6a,b). In Fig. 6a, the three corresponding swaths of divergence and pressure are shown using the same scale as above. Note that the three swaths take place at different times (indicated below the swaths). However, plotting them together on the same map shows the distance traveled by the front in time and its geographical extent.

The front is a remnant of a storm over the Indian Ocean and is first shown on 26 July 1999 around 0000 UTC (left swath). It bears the typical comma-shape signature of mature storms, visible as a line of convergence and as a kink in the isobars in Fig. 6a. The tail of the front is initially oriented southeast-northwest, but 2 days later (28 July 1999 around 0000 UTC), the front has rotated and takes on a more south-north orientation, with its tail reaching southwest Australia. Two 


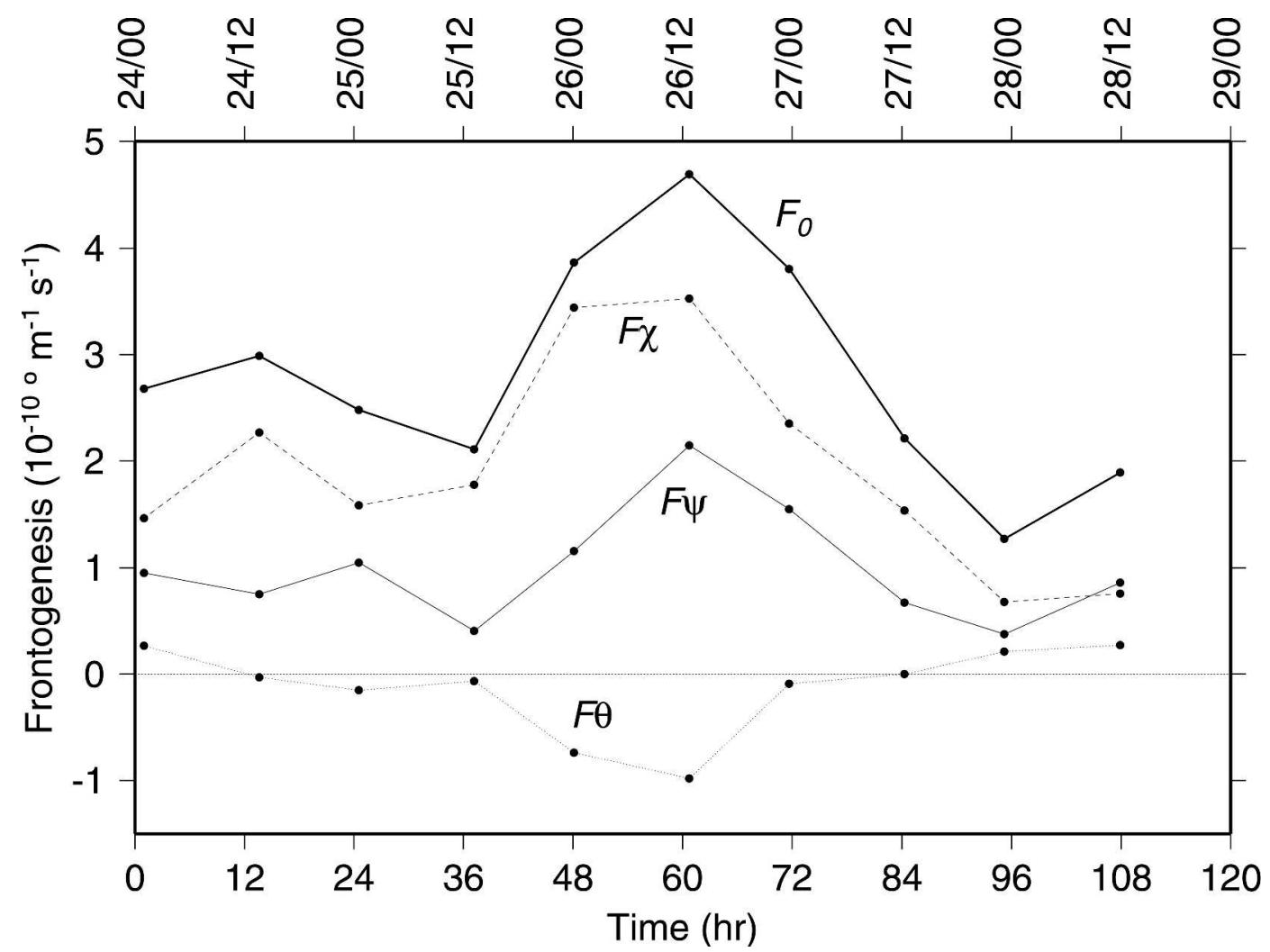

FIG. 5. Frontogenesis due to the nondivergent $\left(F_{v}\right)$, irrotational $\left(F_{\chi}\right)$, environmental $\left(F_{\theta}\right)$, and total wind $\left(F_{0}\right)$. Bottom $x$ axis indicates time from 24 Jul 1999 at 0000 UTC. Top $x$ axis indicates the date as day/time, e.g., 24/12 = $24 \mathrm{Jul} 1999$ at $1200 \mathrm{UTC}$.

days later, the front is oriented south-north and has kept its identity in both the divergence and pressure fields. In the following days, the trough and the front weaken. Over the 8-day life cycle, there is no sign of wave growth along the front.

In Fig. 6b, the 500-hPa relative vorticity and 500-hPa heights are shown at each of the three stages depicted in Fig. 6a. They show that there is a well-formed upperlevel trough corresponding in location to the surface trough. The position of the surface and upper-level troughs reveals that the front tilts westward with height.

The wind partitioning and kinematic analysis are applied to the 14 QS swaths describing the front life cycle. Figure $6 \mathrm{c}$ shows the resulting environmental alongfront stretching. It varies between $0.46 \times 10^{-5} \mathrm{~s}^{-1}$ and $0.85 \times$ $10^{-5} \mathrm{~s}^{-1}$. It never reaches the $0.2 \times 10^{-5} \mathrm{~s}^{-1}$ value observed in the Pacific case (previous section). However, it remains for long periods of time below Bishop and Thorpe's (1994) critical threshold of $0.6 \times$ $10^{-5} \mathrm{~s}^{-1}$.

Finally, Fig. 6d shows frontogenesis due to the total wind $\left(F_{0}\right)$ and to each component $\left(F_{\chi}, F_{\psi}\right.$, and $\left.F_{\theta}\right)$. Here, $F_{0}$ increases, remains relatively strong, and decreases only toward the end of the life cycle. The divergent ageostrophic component $F_{\chi}$ accounts for most of the frontogenesis in the early stages, then decreases toward the end, exhibiting a behavior very similar to that of $F_{\chi}$ in the Pacific case (previous section). In the early stages, $F_{\psi}$ is small, and it increases toward the end. In contrast with the Pacific case, frontogenesis due to the environmental flow $\left(F_{\theta}\right)$ remains overall constant and close to zero. In particular, it does not become significantly frontolytic for a long period of time.

In summary, the behavior of this stable front shares some similarities with the Pacific case. It starts as the remnant of the baroclinic zone associated with a mature storm. It rotates from a southeast-northwest to a north-south orientation and maintains its identity for several days. Frontogenesis occurs in the early stages, with a major role played by the cross-frontal divergent ageostrophic circulation, and decreases with time. However, this front is different, with higher values of the environmental stretching and no significant frontogenesis by the environmental flow. Since large values of vorticity exist at upper levels, these results suggest that the surface conditions might not be optimal in this case for the growth of a vortex on the tail of the front. Since instabilities are likely to exist, we suggest that the environmental stretching deformation might not relax to sufficiently small values for them to grow. 

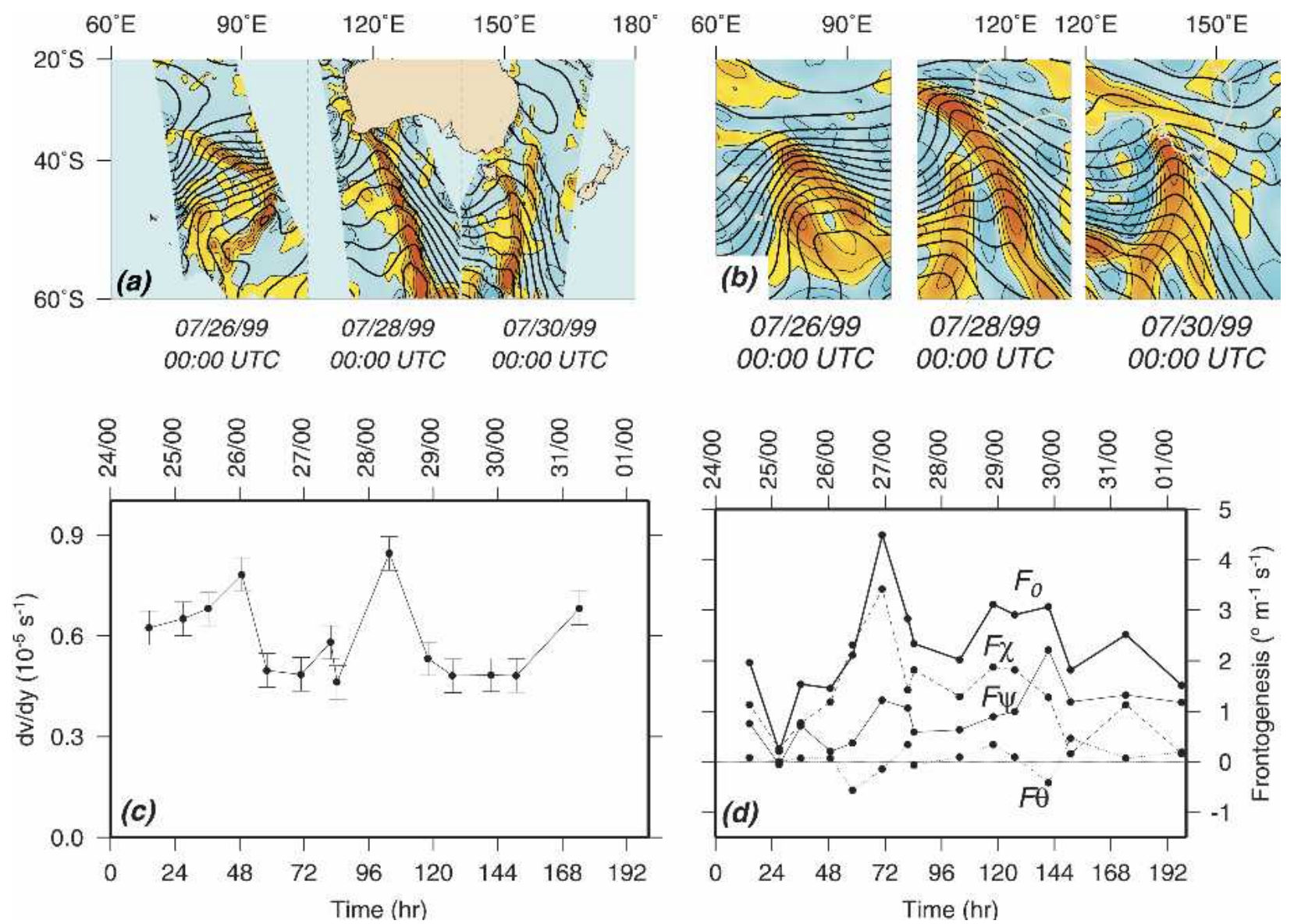

FIG. 6. History of a stable front: (a) surface divergence and pressure from QS at three stages of the front life cycle, (b) 500-hPa relative vorticity and heights, (c) environmental alongfront stretching, (d) frontogenesis. Same scales and contours as in Fig. 3 in (a) and (b). Bottom $x$ axis indicates time from $24 \mathrm{Jul} 1999$ at $0000 \mathrm{UTC}$ in (c) and (d). Top $x$ axis indicates the date as day/time, e.g., 24/12 = 24 Jul 1999 at 1200 UTC.

\section{c. Nondevelopmental wave}

In this last case study, a frontal wave develops on a long-lived cold front but lacks the significant deepening observed in the first case. The life cycle is summarized in Fig. 7, where only three characteristic steps are shown for reference. The front is described with QS divergence and surface pressure in the top row, $500-\mathrm{hPa}$ heights, and relative vorticity in the bottom row.

In Fig. 7a, a mature cyclone is depicted south of the Cape of Good Hope on 24 June 2000 around 0000 UTC. Its cold front curves back to the west and the storm can be seen to have a wide zonal extent on $60^{\circ}$ of longitude. The feature of interest appears in Fig. 7b in the form of a wavy pattern in the convergence line corresponding to the front and a small depression along the front in the pressure field. The position of this small low is highlighted by a circle and an arrow in the 500$\mathrm{hPa}$ plots for future reference. This depression does not deepen and the front maintains its shape (a straight line) and orientation (southeast-northwest) for 4 more days as it moves eastward, before decaying south of
Tasmania. Only one of the remaining time steps is shown for illustration in Fig. 7c.

This case is of interest because it shares many similarities with the first case over the Pacific Ocean; however, the frontal wave does not deepen beyond its initial phase. The wind partitioning and kinematic analysis was carried out on the 11 QS swaths describing the life cycle of this front to compare the two waves. The results are summarized in Fig. 8.

Alongfront stretching by the environmental flow decreases by $0.62 \times 10^{-5} \mathrm{~s}^{-1}$ in $48 \mathrm{~h}$ to reach a minimum value of $0.33 \times 10^{-5} \mathrm{~s}^{-1}$. The overall pattern of decreasing and increasing strain rate resembles the one observed in Fig. 4. As in the first case, the frontal wave appears when the strain rate is a minimum.

Figure $8 \mathrm{~b}$ highlights similarities in frontogenesis with the Pacific Ocean case. Frontogenesis is strong during the first phase of the wave development and then decreases at later times. The divergent ageostrophic component $\left(F_{\chi}\right)$ is the main contributor to frontogenesis, $F_{\psi}$ shows smaller values and variations, and $F_{\theta}$ is close to zero and becomes frontolytic when the first frontal 


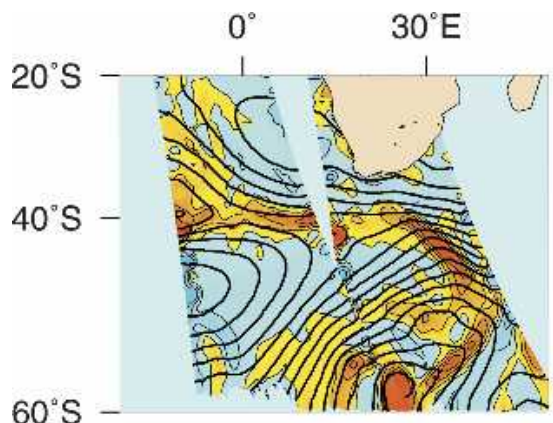

(a) 06/24/00 00:00 UTC

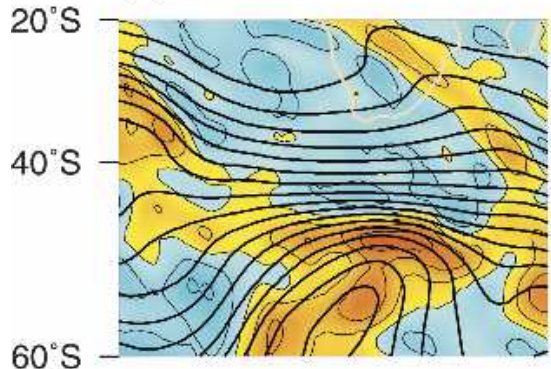

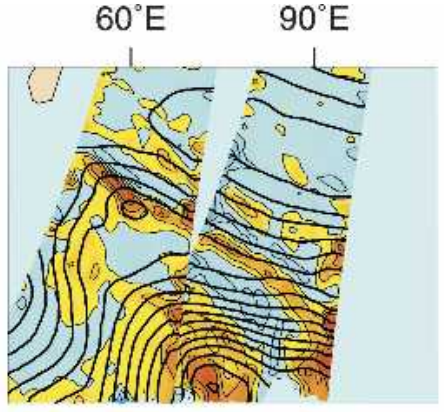

(b) $06 / 26 / 00$ 12:00 UTC

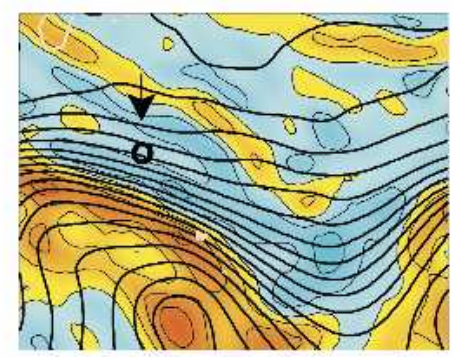

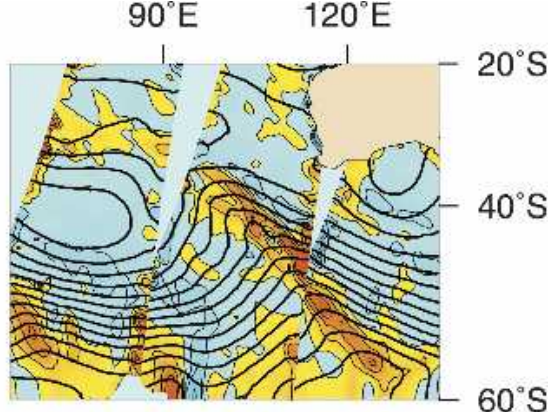

(c) $06 / 29 / 0012: 00$ UTC

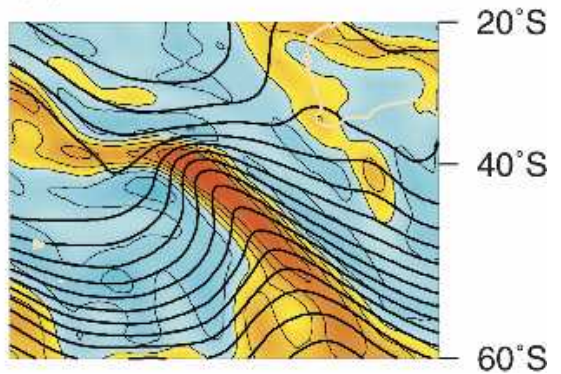

FIG. 7. Three steps in the life cycle of a front over the Indian Ocean. (top) Divergence and surface pressure from QS, and (bottom) 500-hPa heights and relative vorticity. Same scales and contours as in Fig. 3. Arrow and circle in the middle panel of the bottom row indicate the location of the surface frontal wave.

wave grows. Whereas frontogenesis is strong during the strengthening and the rotation of the front (i.e., when the front is "young"), frontogenesis is weak later on (i.e., when the front is "mature").

These results are consistent with our previous discussion of the mechanisms involved in frontal wave growth. The front first strengthens mainly through the convergence of the cross-frontal ageostrophic circulation. Meanwhile, the environmental alongfront stretching decreases and the environmental flow becomes frontolytic; such conditions are favorable for the growth of frontal waves. In this particular case, even though the wave can be observed to grow for $24 \mathrm{~h}$, it does not deepen further into a mature cyclone.

A potential explanation for the limited deepening can be found in Fig. 7b, where the location of the surface wave is shown at upper levels with a circle and an arrow. The wave appears under the upper-level jet, in no particular configuration favorable for growth (like the exit of the jet). No short-wave nor vorticity anomaly is present. Two bands of positive vorticity can be observed, one south, corresponding to the decaying cyclone, and one north, corresponding to an older system. The surface perturbation, however, lies underneath a region of anticyclonic upper-level vorticity. We also verified that the upper-level advection of cyclonic vorticity is small above the surface wave (not shown). This lack of upper-troposphere disturbances is thought to be the main reason why the frontal wave fails to deepen. Although the surface conditions are favorable and the wave grows for $24 \mathrm{~h}$, presumably by drawing energy from the frontal shear, it does not establish a connection with the upper levels; this is apparently a necessary condition for deepening into a secondary cyclone.

\section{Concluding discussion}

Using the uniquely dense ocean surface wind vector measurements from the SeaWinds-on-QuikSCAT scatterometer, kinematic components of the surface wind field can be evaluated with unprecedented resolution and the evolution of fronts and frontal waves can be examined in detail. In this study, three fronts have been analyzed over the Southern Ocean in July 1999 and June 2000.

An attribution technique making use of free-space Green's functions has been applied to the surface wind field in the frontal region. We show that the technique, originally designed for model analyses by Bishop (1996a), can be adapted to scatterometer data. It provides an efficient way of partitioning the wind field into nondivergent and irrotational wind components associated with vorticity and divergence elements in the frontal region on one hand, and a harmonic component associated with the vorticity and divergence elements of the synoptic flow on the other hand. The role played by mesoscale features at the frontal scale and the environmental flow at the synoptic scale can thus be studied separately. Using this technique, and by comparing the evolution of the three fronts, several factors inhibiting 

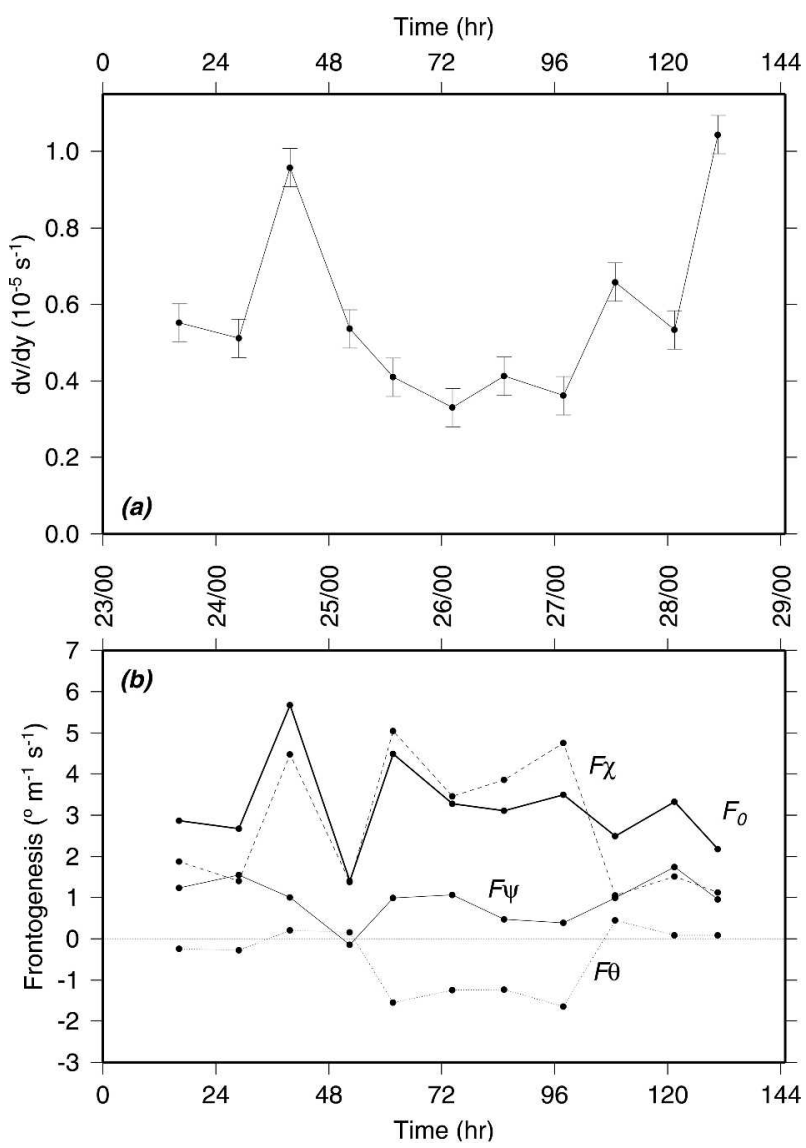

FIG. 8. History of a front over the Indian Ocean: (a) environmental alongfront stretching, and (b) frontogenesis. Top and bottom $x$ axes indicate time from 23 Jun 2000 at 0000 UTC. Middle $x$ axis indicates the date as day/time, e.g., $23 / 12=23$ Jun 2000 at 1200 UTC.

or favoring the growth of frontal waves have been isolated and analyzed. In particular, the large-scale flow plays a role in stretching or relaxing the front and counteracting frontogenesis due to the divergent ageostrophic circulation across the front.

We find that the three marine fronts analyzed in this study shared several characteristics. The fronts are associated with the remnant of a mature cyclone, and they survive their parent cyclone for several days. In doing so, they maintain their identity in surface convergence and inflection of the isobars. Frontogenesis is strong in the early stages and due in large part to the convergence of the cross-frontal ageostrophic circulation at the surface. Frontogenesis decreases with time as the front matures.

The first factor noted is the environmental stretching. In the first front, a frontal wave is shown to grow when the environmental alongfront stretching drops to $0.2 \times$ $10^{-5} \mathrm{~s}^{-1}$. In contrast, the stretching does not decrease significantly in the case of the stable front. This agrees with the general idea that a strong strain rate will "stretch out" the wave and inhibit its growth, whereas a relaxation of the stretching will allow the wave to develop. The present results are consistent with Bishop and Thorpe's (1994) theoretical threshold of $0.6 \times 10^{-5}$ $\mathrm{s}^{-1}$ under which the strain rate should fall before an instability can transition from linear to nonlinear mode and grow significantly. The lower strain rates obtained in the first $\left(0.2 \times 10^{-5} \mathrm{~s}^{-1}\right)$ and third $\left(0.33 \times 10^{-5} \mathrm{~s}^{-1}\right)$ cases can be partly explained by the fact that the partitioning was performed on 10-m observed winds, as opposed to Bishop and Thorpe's idealized model with a free-slip lower boundary condition. Comparisons between 10-m winds and geostrophic winds above the boundary layer ${ }^{3}$ suggest that the 10 -m strain rates are $4 \%$ to $13 \%$ weaker than their geostrophic counterpart. However, the role played by the boundary layer ageostrophy and its relation to frontal wave development are complex. They are the subject of current research and are beyond the scope of this paper.

Along with the environmental alongfront stretching, there is the frontogenetical effect of the environmental flow. Following a similar argument, it is generally thought that as the background flow relaxes, it becomes frontolytical and favors the growth of instabilities. This is also observed here. Moreover, frontogenesis due to the background flow remains close to zero in the case of the stable front. A frontolytic environmental flow appears necessary for instabilities to develop on young fronts experiencing overall frontogenesis otherwise.

In the first case, a fast-moving short wave in the upper-level jet is observed above the frontal wave at the time the frontal wave starts to grow. We hypothesize that the surface wave might have initially drawn energy from the frontal shear, but subsequently deepened due to a favorable configuration between the surface front and the upper levels. The third front, however, lies underneath an upper-level region of anticyclonic vorticity. The surface wave might also have initiated barotropically, but lacks the connection with the upper levels and the baroclinic component necessary for significant growth. These results reinforce the concept proposed in past studies that some frontal waves might be shallow anomalies in their early stages and might only grow significantly if they extend vertically and connect with the upper levels.

To give these statements some generality, one could think of frontal waves as instabilities occurring relatively often in trailing cold fronts. A simple visualization of the QS divergence fields for the July 1999-June 2000 period indeed reveals many such "wavy" patterns. However, the extent to which these instabilities can deepen into secondary cyclones is dictated by the coincidence of several factors, including the stretching deformation and frontolysis by the environmental flow and a connection with the upper levels. Few of the

\footnotetext{
${ }^{3}$ The winds were derived from a planetary boundary layer model.
} 
frontal waves detected in the QS period actually intensify into deep vortices.

The current QS data are certainly a useful dataset for identifying frontal perturbations from the surface wind field. Improved geophysical model functions are currently under development for retrieving surface wind vectors at 12.5 - and $1.2-\mathrm{km}$ grid spacing from backscatter measurements (P. Chang and D. Long 2004, personal communication). With such measurements, the mesoscale structure of fronts and frontal waves could be revealed in even greater detail. Our understanding of secondary cyclone development will be improved by a comprehensive study of the climatology of strain rates and their influence on frontal wave development. Future scatterometer measurements could be used to establish such a climatology.

Acknowledgments. This work was completed as partial fulfillment of the requirements for a doctoral degree at the University of Washington. Jérôme Patoux and Robert A. Brown acknowledge support from NASA Grant NS033A-01, administered through Oregon State University, NASA Grant NAG8-1424, and NASA EOS Grant NAGW-2633. Gregory J. Hakim acknowledges support from NSF Grant ATM-0228804.

\section{REFERENCES}

Atlas, R., S. Bloom, R. N. Hoffman, E. Brin, J. Ardizzone, J. Terry, D. Bungato, and J. C. Jusem, 1999: Geophysical validation of NSCAT winds using atmospheric data and analyses. J. Geophys. Res., 104 (C5), 11,405-11,424.

Bishop, C. H., 1996a: Domain independent attribution. Part I: Reconstructing the wind from estimates of vorticity and divergence using free space Green's functions. J. Atmos. Sci., 53, 241-252.

- 1996b: Domain independent attribution. II: Its value in the verification of dynamical theories of frontal waves and frontogenesis. J. Atmos. Sci., 53, 253-262.

— , and A. J. Thorpe, 1994: Frontal wave stability during moist deformation frontogenesis. Part II: The suppression of nonlinear wave development. J. Atmos. Sci., 51, 874-888.

Bouniol, D., A. Protat, and Y. Lemaître, 1999: Mesoscale dynamics of a deepening secondary cyclone in FASTEX IOP16: Three-dimensional structure retrieved from dropsonde data. Quart. J. Roy. Meteor. Soc., 125, 3535-3562.

— , Y. Lemaître, and A. Protat, 2002: Upper- and lowertroposphere coupling processes involved in the FASTEX IOP16 frontal cyclone. Quart. J. Roy. Meteor. Soc., 128, 12111228.

Brown, R. A., and G. Levy, 1986: Ocean surface pressure fields from satellite sensed winds. Mon. Wea. Rev., 114, 2197-2206.

_ _ and L. Zeng, 1994: Estimating central pressures of oceanic midlatitude cyclones. J. Appl. Meteor., 33, 1088-1095.

Charney, J. G., and M. E. Stern, 1962: On the stability of internal baroclinic jets in a rotating atmosphere. J. Atmos. Sci., 19, 159-172.

Conaty, A. L., J. C. Jusem, L. Takacs, D. Keyser, and R. Atlas, 2001: The structure and evolution of extratropical cyclones, fronts, jet streams, and the tropopause in the GEOS general circulation model. Bull. Amer. Meteor. Soc., 82, 1853-1867.

Evans, M. S., D. Keyser, L. F. Bosart, and G. M. Lackmann, 1994:
A satellite-derived classification scheme for rapid maritime cyclogenesis. Mon. Wea. Rev., 122, 1381-1416.

Hilburn, K. A., M. A. Bourassa, and J. O'Brien, 2003: Development of scatterometer-derived research-quality surface pressures for the Southern Ocean. J. Geophys. Res., 108, 37-51.

Joly, A., 1995: The stability of steady fronts and the adjoint method: Non-modal frontal waves. J. Atmos. Sci., 52, 30823108.

—, and A. J. Thorpe, 1990: Frontal instability generated by tropospheric potential vorticity anomalies. Quart. J. Roy. Meteor. Soc., 116, 525-560.

— application to fronts in developing baroclinic waves. $J$. Atmos. Sci., 48, 163-182.

- and Coauthors, 1997: Definition of the Fronts and Atlantic Storm-Track Experiment (FASTEX). Bull. Amer. Meteor. Soc., 78, 1917-1940.

Keyser, D., and M. J. Pecnick, 1985: A two-dimensional primitive equation model of frontogenesis forced by confluence and horizontal shear. J. Atmos. Sci., 42, 1259-1282.

- M. J. Reeder, and R. J. Reed, 1988: A generalization of Petterssen's function and its relation to the forcing of vertical motion. Mon. Wea. Rev., 116, 762-780.

Kidder, S. Q., and T. H. Vonder Haar, 1995: Satellite Meteorology: An Introduction. Academic Press, 466 pp.

Levy, G., 1989: Surface dynamics of observed maritime fronts. $J$. Atmos. Sci., 46, 1219-1232.

— 1994: Southern Hemisphere low level wind circulation statistics from the Seasat scatterometer. Ann. Geophys., 12, 6579.

— weather from a satellite scatterometer. Mon. Wea. Rev., 119, 2803-2813.

Liu, W. T., 2002: Progress in scatterometer application. J. Oceanogr., 58, 121-136.

Lynch, P., 1989: Partitioning the wind in a limited domain. Mon. Wea. Rev., 117, 1492-1500.

Malardel, S., A. Joly, F. Courbet, and P. Courtier, 1993: Nonlinear evolution of ordinary frontal waves induced by low-level potential vorticity anomalies. Quart. J. Roy. Meteor. Soc., 119, 681-713.

Mallet, I., P. Arbogast, C. Baehr, J.-P. Cammas, and P. Mascart, 1999: Effects of a low-level precursor and frontal stability on cyclogenesis during FASTEX IOP17. Quart. J. Roy. Meteor. Soc., 125, 3415-3437.

McMurdie, L. A., and K. B. Katsaros, 1991: Satellite-derived integrated water-vapor distribution in oceanic midlatitude storms: Variation with region and season. Mon. Wea. Rev., 119, 589-605.

Milliff, R. F., T. J. Hoar, and H. van Loon, 1999: Quasi-stationary wave variability in NSCAT winds. J. Geophys. Res., 104, 11,425-11,435.

Parker, D. J., 1998: Secondary frontal waves in the North Atlantic region: A dynamical perspective of current ideas. Quart. J. Roy. Meteor. Soc., 124, 829-856.

Patoux, J., 2003: Frontal wave development over the Southern Ocean. Ph.D. thesis, University of Washington, $115 \mathrm{pp}$.

_, and R. A. Brown, 2002: A gradient wind correction for surface pressure fields retrieved from scatterometer winds. $J$. Appl. Meteor., 41, 133-143.

, R. C. Foster, and R. A. Brown, 2003: Global pressure fields from scatterometer winds. J. Appl. Meteor., 42, 813-826.

Renfrew, I. A., A. J. Thorpe, and C. H. Bishop, 1997: The role of environmental flow in the development of secondary frontal cyclones. Quart. J. Roy. Meteor. Soc., 123, 1653-1675.

Rivals, H., J.-P. Camas, and I. A. Renfrew, 1998: Secondary cyclogenesis: The initiation phase of a frontal wave observed over the eastern Atlantic. Quart. J. Roy. Meteor. Soc., 124, 243-267. 
Schär, C., and H. C. Davies, 1990: An instability of mature cold fronts. J. Atmos. Sci., 47, 929-950.

Thorncroft, C. D., and B. J. Hoskins, 1990: Frontal cyclogenesis. J. Atmos. Sci., 47, 2317-2336.

Wentz, F. J., and D. K. Smith, 1998: Rain effect on NSCAT sigma-0 measurements. NSCAT Science Team Meeting Report, Jet Propulsion Laboratory, California Institute of Technology, Pasadena, CA.

Yeh, H.-C., G.-J. Chen, and W. Liu, 2002: Kinematic character- istics of a mei-yu front detected by the QuikSCAT oceanic winds. Mon. Wea. Rev., 130, 700-711.

Yuan, X., D. J. Martinson, and W. T. Liu, 1999: The effect of air-sea interaction on winter 1996 Southern Ocean subpolar storm distribution. J. Geophys. Res., 104, 1991-2007.

Zierden, D. F., M. A. Bourassa, and J. J. O’Brien, 2000: Cyclone surface pressure fields and frontogenesis from NASA scatterometer (NSCAT) winds. J. Geophys. Res., 105, $23967-$ 23981. 